\title{
Multi-frequency impedance for the prediction of extracellular water and total body water
}

\author{
BY PAUL DEURENBERG ${ }^{1}$, ANNA TAGLIABUE ${ }^{2}$ \\ AND FRANS J.M.SCHOUTEN ${ }^{1}$ \\ ${ }^{1}$ Department of Human Nutrition, Wageningen Agricultural University, Bomenweg 2, \\ 6703 HD Wageningen, The Netherlands \\ ${ }^{2}$ Department of Human Nutrition, University of Pavia, Via Bassi 21, 27100 Pavia, Italy
}

(Received 17 January 1994 - Revised 27 June 1994-Accepted 7 July 1994)

\begin{abstract}
The relationship between total body water (TBW) and extracellular water (ECW), measured by deuterium oxide dilution and bromide dilution respectively, and impedance and impedance index (height ${ }^{2}$ /impedance) at 1, 5, 50 and $100 \mathrm{kHz}$ was studied. After correction for TBW, ECW was correlated only with the impedance index at 1 and $5 \mathrm{kHz}$. After correction for ECW, TBW was best correlated with the impedance index at $100 \mathrm{kHz}$. The correlation of body-water compartments with impedance values obtained with modelling programs was lower than with measured impedance values. Prediction formulas for ECW (at 1 and $5 \mathrm{kHz}$ ) and TBW (at 50 and $100 \mathrm{kHz}$ ) were developed. The prediction errors for ECW and TBW were 1.0 and $1.7 \mathrm{~kg}$ respectively (coefficient of variation $5 \%$ ). The residuals of both ECW and TBW were related to the ECW/TBW value. Application of the prediction formulas in a population, independently measured, revealed a slight overestimation of TBW and ECW, which could be largely explained by differences in the validation group in body-water distribution and in body build. The ratio of impedance at $1 \mathrm{kHz}$ to impedance at $100 \mathrm{kHz}$ was correlated with body-water distribution (ECW/TBW). The relation is however not strong enough to be useful as a predictor. It is concluded that an independent prediction of ECW and TBW, using impedance at low and high frequency respectively, is possible, but that the bias depends on the body-water distribution and body build of the measured subject.
\end{abstract}

Body composition: Body water: Extracellular water: Multi-frequency impedance

Since the early work of Thomasset (1962), Hoffer et al. (1969), Nyboer (1970) and the study of Lukaski et al. (1985), bio-electrical impedance has become a popular method for assessing body composition. In impedance methodology a small alternating current, normally at a frequency of $50 \mathrm{kHz}$, is applied to the body, and the resistance or impedance of the body to that current, which is inversely proportional to the amount of body water, is measured (Lukaski et al. 1985). Numerous studies in healthy subjects have been published showing that the impedance methodology is able to predict body water (Lukaski et al. 1985; Kushner et al. 1992) or fat-free mass (Segal et al. 1988; Deurenberg et al. 1991) with a reasonable precision. However, prediction formulas are population specific (Deurenberg et al. 1991; Svendson et al. 1991). Owing to differences in specific resistivity of the extra- and intracellular water (Deurenberg et al. 1989), incomplete conduction of the intracellular fluid at $50 \mathrm{kHz}$ (Thomasset, 1962), and because the extracellular water: intracellular water ratio in the healthy body depends on sex and age, the prediction formulas for body water are age- and sex-dependent (Segal et al. 1988; Deurenberg et al. 1991). For a few years multi-frequency impedance instruments have been commercially available. At low frequencies the alternating current is unable to penetrate the cell membrane, owing to the capacitive properties of the membrane (Thomasset, 1962; Nyboer, 1970; Jenin et al. 1975; Settle et al. 1980). This implies that, at low frequency, body 
impedance is a measure of extracellular water only. At higher frequencies the capacitive resistance of the cell membrane diminishes and finally disappears. Hence, the body impedance at very high frequency is a measure of total body water. The advantage of multifrequency impedance measurements could be that assessments of body-water compartments and body-water distribution are obtained, which is important in the assessment of body composition in, for example, the diseased. Segal et al. (1991) showed that extracellular water and total body water could be predicted independently at 5 and $100 \mathrm{kHz}$ respectively. Her study was performed in a relatively small group and in males only. In an earlier study we showed that from multi-frequency scans the theoretical extra- and intracellular resistance can be calculated using mathematical modelling techniques, with which a prediction of body-water compartments is possible. This approach needs, however, adequate computer software and is time-consuming. Moreover, the modelling calculation is due to calculation error which limits the predictive power of the calculated impedance values (Deurenberg, 1994).

The aim of the present study was to investigate the relationship of extracellular water and total body water, measured by dilution techniques, with body impedance at distinct frequencies in order to develop simple prediction formulas for extracellular water and total body water. The developed prediction formulas were validated in a different population, measured in another laboratory under comparable conditions.

\section{SUBJECTS AND METHODS}

The data from 139 subjects were used to study the relationship between body-water compartments and body impedance ('regression group'). They were all healthy volunteers and were measured at the Department of Human Nutrition in Wageningen, The Netherlands. The developed prediction formulas were validated in a group of forty healthy subjects ('validation group'), measured at the Department of Human Nutrition at the University of Pavia, Italy. At both institutes the same study protocol was followed. Table 1 gives some characteristics of the subjects. The study was approved by the Medical Ethics Committees of both institutes.

All measurements were performed on the same day, in the morning, after an overnight fast. Body weight and body height were measured to the nearest $0.1 \mathrm{~kg}$ and $0.001 \mathrm{~m}$ respectively, using a digital scale and a wall-mounted stadiometer respectively. BMI was calculated as weight $/$ height ${ }^{2}\left(\mathrm{~kg} / \mathrm{m}^{2}\right)$. Body impedance $(\Omega)$ was measured at the left side of the body, using self-adhesive ECG-electrodes with a surface area of $500 \mathrm{~mm}^{2}$ (Littman 2325 VP, 3M, St. Paul, MN, USA) with a Human-IM Scan impedance analyser (Dietosytem, Milano, Italy). An impedance scan (Fig. 1) was made at frequencies ranging from $0.3 \mathrm{kHz}$ to $100 \mathrm{kHz}$. Only impedance data at $1,5,50$ and $100 \mathrm{kHz}$ were used in the statistics of the present study. The impedance index was calculated as height ${ }^{2} /$ impedance $\left(\mathrm{m}^{2} / \Omega\right)$. Total body water (TBW) and extracellular water (ECW) were measured using dilution techniques. A cocktail of an accurately-weighed dose of $15 \mathrm{~g}$ deuterium oxide and $900 \mathrm{mg}$ bromide $(1.34 \mathrm{~g}$ as $\mathrm{KBr}$ ) was taken orally by the subjects. After $2 \cdot 5-3 \mathrm{~h}$ dilution time a venous blood sample was taken, the plasma was separated and was stored at $-80^{\circ}$ until analysed.

Deuterium in plasma was determined after sublimation by infrared spectroscopy (Lukaski \& Johnson, 1985). Total body water was calculated using a correction factor $(0.95)$ for non-aqueous dilution (Forbes, 1987). Bromide in plasma was determined after ultrafiltration by HPLC (Miller \& Cappon, 1984). Extracellular water was calculated using a correction factor of 0.9 for non-extracellular distribution and a correction of 0.95 for the DONNAN effect (Forbes, 1987). The deuterium and bromide analyses were all performed in the same laboratory (Wageningen Agricultural University). 
Table 1. Characteristics of the populations

(Mean values and standard deviations)

\begin{tabular}{|c|c|c|c|c|c|c|c|c|}
\hline & \multicolumn{4}{|c|}{ Prediction group } & \multicolumn{4}{|c|}{ Validation group } \\
\hline & \multicolumn{2}{|c|}{ Males } & \multicolumn{2}{|c|}{ Females } & \multicolumn{2}{|c|}{ Males } & \multicolumn{2}{|l|}{ Females } \\
\hline & Mean & SD & Mean & SD & Mean & SD & Mean & SD \\
\hline Age (years) & $26 \cdot 2$ & $7 \cdot 3$ & 25.9 & 5.8 & $21 \cdot 7++t$ & 1.5 & $22 \cdot 2+t \dagger$ & $2 \cdot 4$ \\
\hline Weight $(\mathrm{kg})$ & $75 \cdot 0$ & $8 \cdot 7$ & $66 \cdot 0^{* * *}$ & $11 \cdot 0$ & $72 \cdot 7$ & $8 \cdot 6$ & $56 \cdot 6^{* * *+\dagger \dagger}$ & $6 \cdot 3$ \\
\hline Height (m) & $1 \cdot 84$ & 0.06 & $1.69 * * *$ & 0.06 & $1 \cdot 78+1+$ & 0.06 & $1.63^{* * *+\dagger \dagger}$ & 0.06 \\
\hline $\mathrm{BMI}\left(\mathrm{kg} / \mathrm{m}^{2}\right)$ & $22 \cdot 2$ & $2 \cdot 2$ & $23 \cdot 0$ & $4 \cdot 4$ & $23 \cdot 1$ & $2 \cdot 8$ & 21.6 & 1.7 \\
\hline Body fat $(\%)$ & $13 \cdot 1$ & 48 & $27 \cdot 2 * * *$ & 6.9 & $24 \cdot 3+1+$ & 5.9 & $26 \cdot 3$ & $4 \cdot 7$ \\
\hline TBW (kg) & $45 \cdot 3$ & $4 \cdot 8$ & $33 \cdot 1^{* * *}$ & $3 \cdot 3$ & $42 \cdot 2+t+$ & 3.6 & $29 \cdot 0 * * *+1+$ & $2 \cdot 9$ \\
\hline $\mathrm{ECW}(\mathrm{kg})$ & $18 \cdot 2$ & $2 \cdot 2$ & $14 \cdot 4^{* * *}$ & $1 \cdot 4$ & $16 \cdot 3+\dagger \dagger$ & $1 \cdot 2$ & $11 \cdot 8 * * *+\dagger \dagger$ & $1 \cdot 1$ \\
\hline ECW/TBW & 0.40 & 0.02 & $0.43 * * *$ & 0.02 & $0.39+1+$ & 0.02 & $0-41 * * *+\dagger \dagger$ & 0.03 \\
\hline TBW/height $(\mathrm{kg} / \mathrm{m})$ & $24 \cdot 6$ & $2 \cdot 1$ & $19 \cdot 5^{* * *}$ & 1.9 & $23 \cdot 8 * * *+1 \dagger$ & 1.7 & $17 \cdot 8$ & $1 \cdot 3$ \\
\hline ECW/height $(\mathrm{kg} / \mathrm{m})$ & $9 \cdot 9$ & $1 \cdot 0$ & $8 \cdot 5^{* * *}$ & 0.8 & $9 \cdot 2$ & 0.6 & $7 \cdot 2 * * *+1+$ & 0.5 \\
\hline$Z_{1}(\Omega)$ & 584 & 56 & $688 * * *$ & 74 & 595 & 51 & $709 * * *$ & 52 \\
\hline$Z_{5}(\Omega)$ & 565 & 50 & $673 * * *$ & 70 & 579 & 50 & $693 * * *$ & 52 \\
\hline$Z_{50}(\Omega)$ & 482 & 44 & $589 * * *$ & 63 & 501 & 44 & $615^{* * *}$ & 49 \\
\hline$Z_{100}(\Omega)$ & 449 & 42 & $552^{* * *}$ & 61 & 466 & 42 & $575^{* * *}$ & 46 \\
\hline$Z_{1} / Z_{100}$ & $1 \cdot 30$ & 0.03 & $1 \cdot 24 * * *$ & 0.06 & $1.28+t \dagger$ & 0.03 & $1.23 * * *$ & 0.02 \\
\hline
\end{tabular}

TBW, total body water; ECW, extracellular water; $\mathrm{Z}_{1}$, impedance at $1 \mathrm{kHz} ; \mathrm{Z}_{5}$, impedance at $5 \mathrm{kHz} ; \mathrm{Z}_{50}$, impedance at $50 \mathrm{kHz} ; Z_{100}$, impedance at $100 \mathrm{kHz}$.

*** Mean values were significantly different from those for males, $P<0.001$.

$+\dagger \dagger$ Mean values were significantly different from those of the corresponding gender in the prediction group, $P<0.001$.

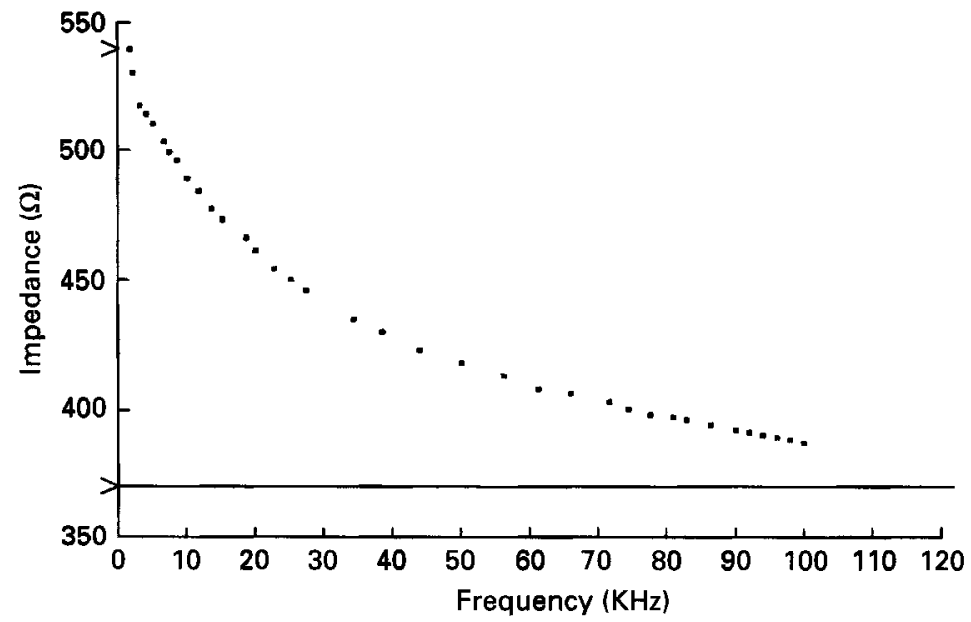

Fig. 1. Body impedance in relation to frequency. $>, R_{e}$, computed theoretical extracellular resistance; ,$- \mathrm{R}_{\text {tot }}$, computed theoretical total resistance (Deurenberg, 1994).

Body fat in the regression group was determined by densitometry, using Siri's (1961) equation to calculate body fat from body density. The technique is described in detail elsewhere (Deurenberg et al. 1991). In the validation group body fat was assessed from skinfold thickness using the Durnin \& Womersley (1974) equations. 
Statistical calculations were performed using the SPSS/PC (1990) software program. Differences in variables between groups were tested for significance using ANOVA techniques. Differences between variables within groups were tested with paired $t$ tests. Stepwise multiple linear regression was performed to study the relationship between measured water compartments and other variables. Sex was coded as females 0 , males 1 . Correlations are Pearson's product moment correlations or partial multiple correlations (Kleinbaum \& Kupper, 1978). The Bland \& Altman (1986) procedure was used in the validation of the prediction formulas. Values are given as means and standard deviations. The level of two-tailed significance is 0.05.

\section{RESULTS}

Table 1 gives some characteristics for the regression group and the validation group for males and females separately. The normal differences in body composition between males and females were observed. Compared with the regression group the validation group was younger, had a lower body height, lower TBW, ECW and a lower ECW/TBW value in both males and females. The females in the validation group also had a lower body weight, whereas the males had a significantly higher percentage body fat compared with the regression group. The striking features are the differences in body-water distribution (ECW/TBW) and in the TBW/height or ECW/height values between the groups in both sexes.

In Table 2 the correlation coefficients of ECW and TBW with impedance $(\Omega)$ and with impedance index $\left(\mathrm{m}^{2} / \Omega\right)$ at different frequencies are given. As ECW and TBW are highly intercorrelated (in this population $r 0.93, P<0.0001$ ), the partial correlations of ECW with impedance and impedance index after correction for the amount of TBW, and the partial correlation of TBW with impedance and impedance index after correction for ECW were also calculated. It can be seen that after correction for TBW, ECW was only significantly related with the impedance index at low frequency $(1 \mathrm{kHz}$ and, less pronounced, $5 \mathrm{kHz})$. The partial correlation of TBW after correction for ECW with the impedance index at different frequencies increases with frequency. The partial correlation of ECW with impedance index $\mathrm{H}^{2} / \mathrm{R}_{\mathrm{e}}\left(\mathrm{R}_{\mathrm{e}}\right.$ obtained by modelling, see Fig. 1) was $0 \cdot 22$. The partial correlation of TBW with the impedance index $\mathbf{H}^{2} / \mathbf{R}_{\text {tot }}\left(\mathrm{R}_{\text {tot }}\right.$ obtained by modelling, see Fig. 1) was $0 \cdot 74$. These correlations were not better compared with the correlations with measured impedance values. These results show that low-frequency impedance measurements enable the independent prediction of ECW whereas high-frequency impedance is predictive for TBW.

Table 3 gives the regression coefficients of the stepwise multiple regression for the prediction of TBW (at 100 and $50 \mathrm{kHz}$ ) and ECW (at 5 and $1 \mathrm{kHz}$ ) from impedance index, body weight, age and sex. The prediction of $\mathrm{TBW}$ at $100 \mathrm{kHz}$ is slightly better than the prediction at $50 \mathrm{kHz}$, both with impedance index as single independent variable, as well as with weight, age and sex included as independent variables. The prediction of ECW at $1 \mathrm{kHz}$ is slightly better than the prediction at $5 \mathrm{kHz}$. Sex did not contribute significantly in the prediction of ECW.

The prediction formulas shown in Table 3 were internally validated in males and females, in different age groups and in groups with different BMI values. In all subgroups there were no significant differences between measured and predicted values, except in the obese subjects (BMI $\left.>30 \mathrm{~kg} / \mathrm{m}^{2}, n 6\right)$, in which TBW (2.2 (SD 1.6) kg) and ECW (1.3 (SD 0.6) kg) were significantly $(P<0.05)$ underestimated when predicted from the impedance index only. When the complete prediction formulas were used the difference between measured and predicted values were also not significant in the obese subjects. When the prediction 
Table 2. Pearson's correlations and partial correlations between total body water and extracellular water and impedance and impedance index at different frequencies*

\begin{tabular}{ccccccccc}
\hline \hline & $\mathrm{Z}_{\mathbf{1}}$ & $\mathrm{Z}_{\mathbf{5}}$ & \multicolumn{1}{c}{$\mathrm{Z}_{\mathbf{5 0}}$} & $\mathrm{Z}_{\mathbf{1 0 0}}$ & $\mathbf{H}^{2} / \mathbf{Z}_{\mathbf{1}}$ & $\mathbf{H}^{\mathbf{2}} / \mathbf{Z}_{\mathbf{5}}$ & $\mathbf{H}^{\mathbf{2} / \mathbf{Z}_{\mathbf{5 0}}}$ & $\mathbf{H}^{2} / \mathbf{Z}_{\mathbf{1 0 0}}$ \\
\hline ECW & -0.74 & -0.74 & -0.74 & -0.74 & 0.91 & 0.90 & 0.90 & 0.90 \\
TBW & -0.74 & -0.77 & -0.80 & -0.81 & 0.93 & 0.94 & 0.95 & 0.96 \\
ECW & -0.17 & -0.06 & 0.02 & 0.05 & 0.31 & 0.19 & 0.09 & 0.05 \\
TBW + & -0.23 & -0.36 & -0.45 & -0.47 & 0.53 & 0.65 & 0.73 & 0.75 \\
\hline
\end{tabular}

TBW, total body water; ECW, extracellular water; $Z_{1}$, impedance at $1 \mathrm{kHz} ; Z_{5}$, impedance at $5 \mathrm{kHz} ; Z_{50}$, impedance at $50 \mathrm{kHz} ; \mathrm{Z}_{100}$, impedance at $100 \mathrm{kHz}, \mathrm{H}^{2} / \mathrm{Z}_{1}$; impedance index at $1 \mathrm{kHz} ; \mathrm{H}^{2} / Z_{5}$, impedance index at $5 \mathrm{kHz} ; \mathrm{H}^{2} / \mathrm{Z}_{50}$, impedance index at $50 \mathrm{kHz} ; \mathrm{H}^{2} / \mathrm{Z}_{100}$, impedance index at $100 \mathrm{kHz}$.

* Values $>0.17: P<0.05$; values $>0.23: P<0.01$; values $>0.31: P<0.001$.

$\dagger$ Correlation after correction for total body water.

$\ddagger$ Correlation after correction for extracellular water.

Table 3. Stepwise multiple regression for the prediction of total body water and extracellular water from impedance index, weight, age and sex*

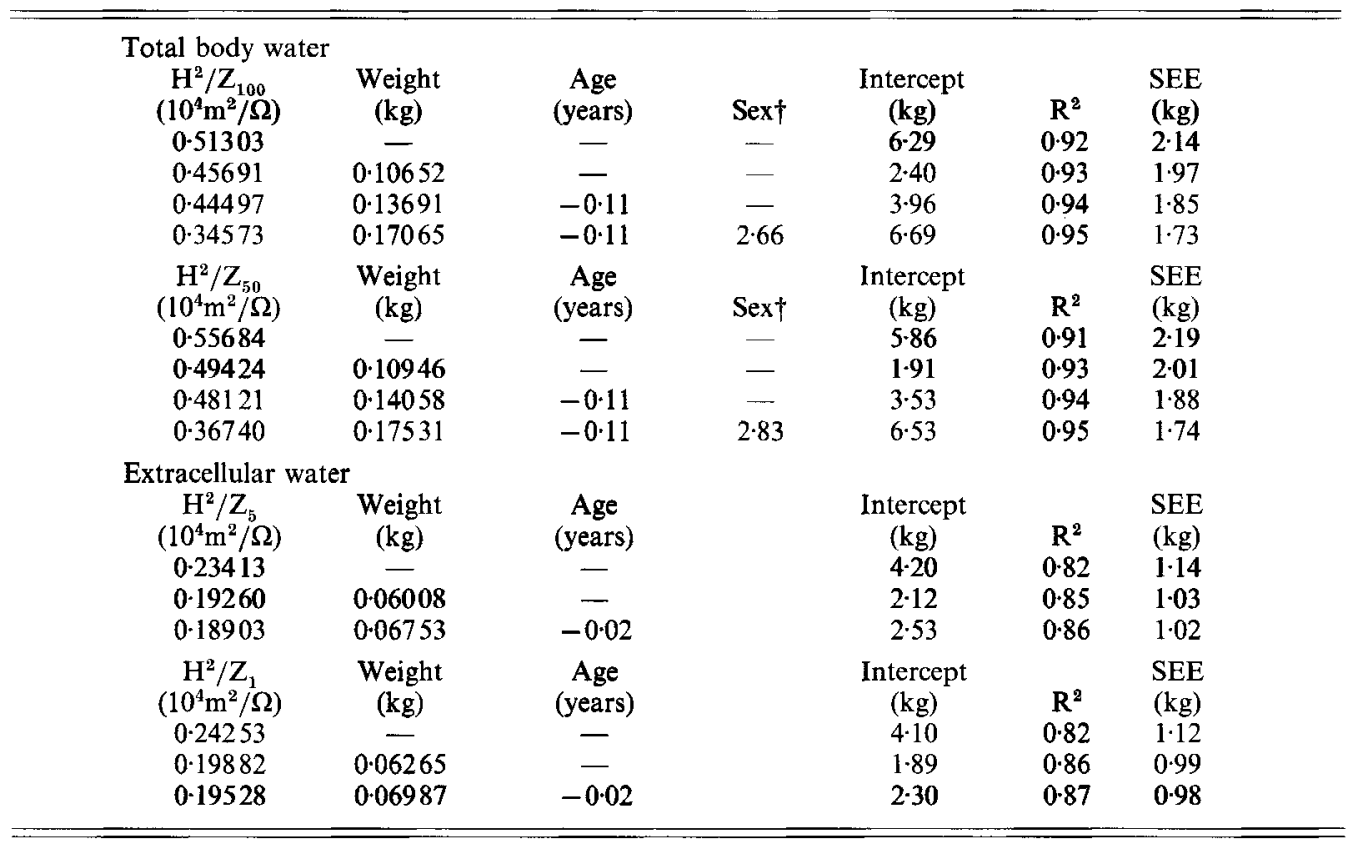

$\mathrm{H}^{2} / \mathrm{Z}_{100}$, impedance index at $100 \mathrm{kHz} ; \mathrm{H}^{2} / \mathrm{Z}_{50}$, impedance index at $50 \mathrm{kHz} ; \mathrm{H}^{2} / \mathrm{Z}_{5}$, impedance index at $5 \mathrm{kHz}$; $\mathrm{H}^{2} / \mathrm{Z}_{1}$, impedance index at $1 \mathrm{kHz}$, SEE, standard error of the estimate.

* Independent variables listed in order of entrance $(P<0.05)$.

$\dagger$ Females $=0$, males $=1$.

formulas were applied to the validation group, TBW was correctly predicted when using the formula with impedance index only $(100 \mathrm{kHz}$ : difference 0.1 (SD 2.2) $\mathrm{kg} ; 50 \mathrm{kHz}$ : difference 0.0 (SD $2 \cdot 3) \mathrm{kg}$ ), but slightly overestimated with the complete formula $(100 \mathrm{kHz}$ and $50 \mathrm{kHz}$ : difference $0.7(\operatorname{SD~} 1.5) \mathrm{kg}, P<0.05)$. ECW was always overestimated by $1 \cdot 1$ (SD 0.8) kg independent of the formula used. Fig. 2 shows that the slight overestimation 

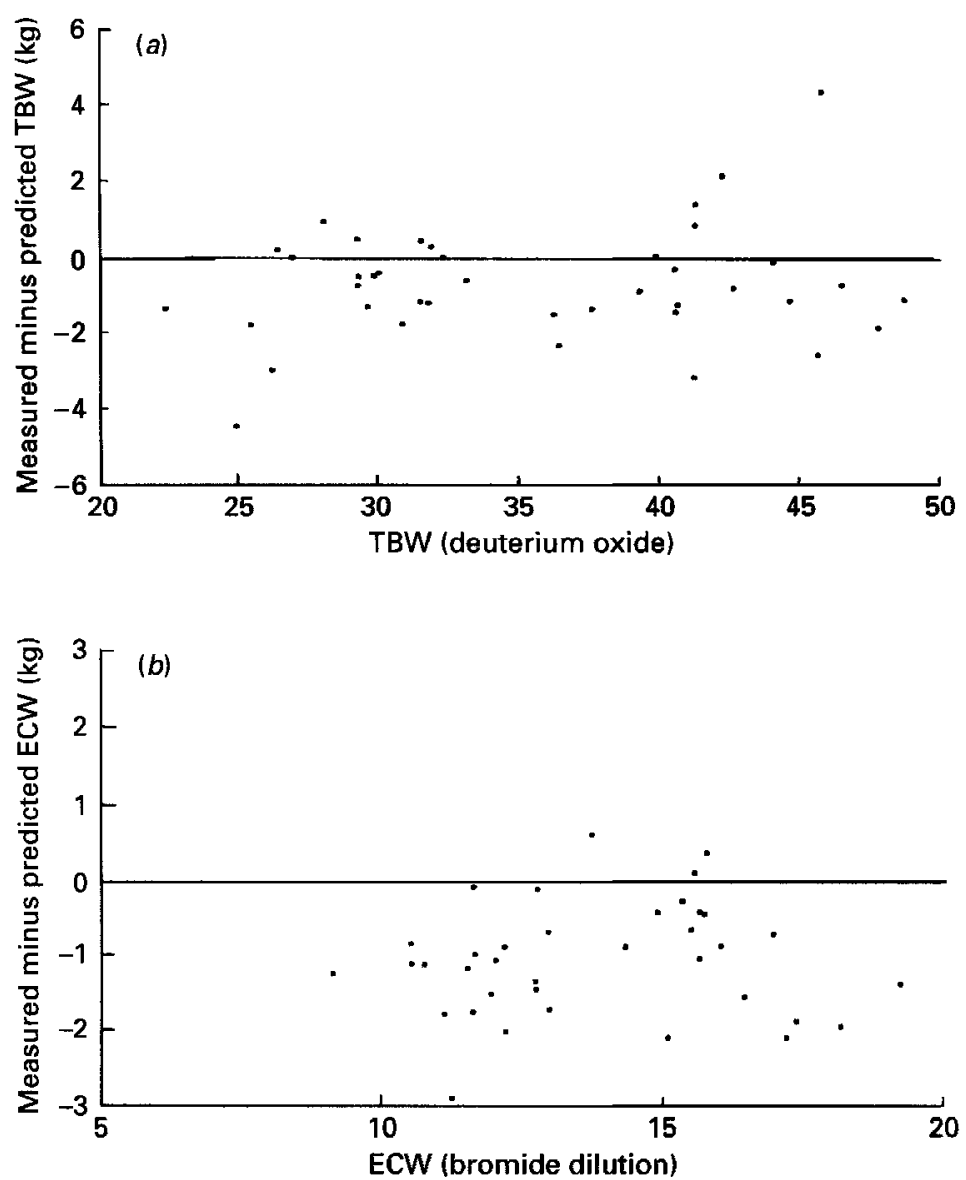

Fig. 2. Individual differences $(\mathrm{kg})$ between ( $a$ ) measured and predicted total body water (TBW) at $100 \mathrm{kHz}$ and $(b)$ measured and predicted extracellular water $(\mathrm{ECW})$ at $1 \mathrm{kHz}$.

of TBW (at $100 \mathrm{kHz}$ ) and ECW (at $1 \mathrm{kHz}$ ) in the validation group was not dependent on the level of the body-water compartment. The residuals of predicted TBW and ECW at 50 and $5 \mathrm{kHz}$ respectively showed the same picture (not shown). Of importance is the correlation of the bias (measured-predicted) of the predicted water compartments with ECW $/$ TBW, which was $-0.49,-0.48,+0.43$ and +0.45 for the predicted TBW and ECW at $100,50,5$ and $1 \mathrm{kHz}$ respectively (all significant, $P<0.001$ ). These correlations were $-0.15(P<0.05),-0.19(P<0.05),+0.55(P<0.001)$ and $+0.45(P<0.001)$ in the regression group.

Prediction formulas from the literature slightly overestimated TBW by between 1.0 (SD 2.2) $\mathrm{kg}$ (regression group) and 0.4 (SD 2.0) kg (validation group) with the formula of Kushner et al. (1992) and 3.2 (SD 2.0$) \mathrm{kg}$ (regression group) and 2.9 (SD 1.8) kg (validation group) with the formula of Segal et al. (1991). The formula of Lukaski et al. (1985) gave intermediate values. ECW $/ \mathrm{TBW}$ was significantly correlated $(r-0.64, \mathrm{P}<0.0001)$ with the term impedance at $1 \mathrm{kHz} /$ impedance at $100 \mathrm{kHz}\left(Z_{1} / Z_{100}\right)$, which is shown in Fig. 3 . This impedance term was significantly different between males and females in each group (Table 1). The difference in this impedance term reflects the difference in body-water distribution (ECW/TBW). 


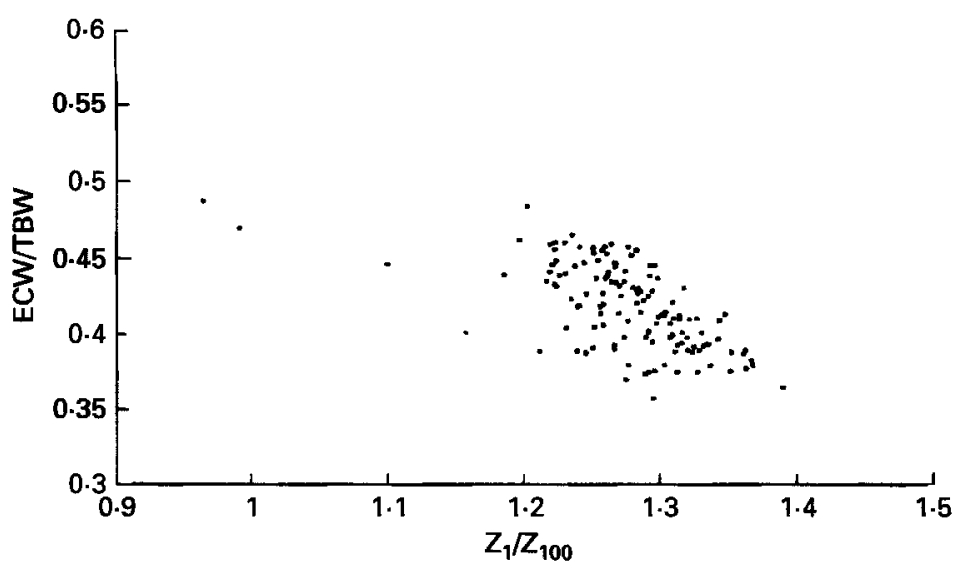

Fig. 3. Body water distribution (extracellular water/total body water, ECW/TBW) in relation to impedance at $1 \mathrm{kHz} /$ impedance at $100 \mathrm{kHz}\left(Z_{1} / Z_{100}\right)$. The relationship is described by the equation $Y=-0 \cdot 32 X+0 \cdot 82(R 0 \cdot 64$, SEE 0.02).

\section{DISCUSSION}

Fig. 1 gives a typical example of the relationship between measured body impedance and the frequency of the current. From the higher impedance values at low frequencies it can be concluded that the conductive part of the body is smaller at low frequencies: the current is not able to penetrate the cell membrane at low frequencies. It can also be seen that even at $100 \mathrm{kHz}$ the current does not penetrate the cell membrane completely, and at $1 \mathrm{kHz}$ probably already a small part of the current passes the membrane. The valid measurement of impedance at very low and very high frequencies is technically very difficult (Schwan, 1963). Modelling programs can be used to calculate the theoretical impedance values at frequency zero and at frequency infinity from the impedance scan. However, it was shown (Deurenberg, 1994) that the errors in these calculated impedances (coefficient of variation 1-3\%) contra-act the theoretical advantages. This explains the observed lower partial correlations of body-water compartments with the impedance indices using impedance values obtained by modelling programs.

In the present study impedance indices at all frequencies were highly correlated with both ECW and TBW (Table 2). As ECW and TBW are highly intercorrelated, partial correlation coefficients (Kleinbaum \& Kupper, 1978) were computed between ECW and impedance indexes at different frequencies, after correction for TBW and vice versa. It was shown that the impedance index at $1 \mathrm{kHz}$, and to a lesser extent also at $5 \mathrm{kHz}$, is related to $\mathrm{ECW}$, independent of the total amount of body water (Table 2). Consequently, ECW can be best predicted at those frequencies. Although at lower frequencies ECW is measured, TBW is also strongly related to impedance index at low frequencies, even after correction for the amount of ECW (Table 2). This can be explained by the fact that ECW is part of TBW. Theoretically it can be expected that at higher frequencies such as $100 \mathrm{kHz}$ the correlation of impedance index and TBW is better, and hence the prediction of TBW is also better. Unfortunately however, due to technical limitations and to interactions between electrodes and skin (Schwan, 1963), the instruments available today are not able to measure impedances reliably at frequencies higher than 100 to $200 \mathrm{kHz}$ (Van Marken Lichtenbelt et al. 1994).

The prediction of ECW from impedance index at 5 or $1 \mathrm{kHz}$ is possible with a prediction error of about $1 \mathrm{~kg}$, which equals a coefficient of variation (CV) of about $5 \%$. The prediction error in TBW is $1.7 \mathrm{~kg}$ (CV 5\%). 
Total body impedance is largely determined by the impedance values of the arms and the leg (Baumgartner et al. 1989; Fuller \& Elia, 1989), whereas the larger part of the body water is located in the trunk. The relative (to body height) extremity length may differ between populations and also within populations between age groups (e.g. senile kyphosis), and may influence the relationship between impedance and body water. The prediction of ECW from impedance index alone was improved when body weight and age were added as independent variables. These additional variables probably correct for differences in body build which are not accounted for by the impedance index, which is only a crude measurement. The prediction of TBW could also be improved by the additional factors body weight, age and sex. Again it can be argued that these additional independent predictors correct for differences in body build, but, because at 50 and at $100 \mathrm{kHz}$ not all TBW is measured (see Fig. 1), sex and age may also reflect the difference in body water distribution at different ages and between sexes. From the observed negative correlations in both the regression group and the validation group between the bias (measured minus predicted) in TBW and ECW/TBW it can be concluded that at the frequencies used the current does not penetrate the cell membranes fully. Thus TBW is predicted from an impedance measurement related mainly to $\mathrm{ECW}$, assuming a constant relationship between ECW and TBW in the group in which the prediction formula is developed. This has important consequences for the validity of the prediction formulas in a population with a different body-water distribution. The positive correlation between the bias (measured minus predicted) in ECW shows that at 5 and $1 \mathrm{kHz}$ intracellular water is also partly measured. It could also be that although the current at low frequency does not pass the cell membrane, there is some interaction between the membrane and the current, depending on the fibre direction (Rush et al. 1963; Settle et al. 1980). It can be concluded that the prediction of TBW and ECW will always depend on the body-water distribution, which limits the quantitative prediction of changes in body water when these changes are coincidental with changes in water distribution, or when measuring diseased subjects with disturbed water distribution (Deurenberg et al. 1994). The developed prediction formulas for TBW and ECW slightly overestimated the measured TBW and ECW in the validation group. As, in the present study, the same protocol and the same instruments were used, it may be assumed that differences between measured and predicted variables are due to factors other than methodology. There are significant differences in several variables (Table 1) between the regression and the validation groups, which may be partly responsible for the differences between predicted and measured values. The most striking differences between the groups were the differences in ECW/TBW in both sexes and the differences in the TBW/height and ECW/height terms (Table 1). The differences in these variables were found to be highly responsible for the bias in predicted body-water compartments. The difference between measured TBW and predicted TBW of -0.7 (SD 1.5) $\mathrm{kg}(P<0.05)$ decreased to -0.3 (SD 1.6) $\mathrm{kg}$ (not significant) after correction for differences in TBW/height. The differences between measured and predicted ECW decreased from $-1.1($ SD 0.8$) \mathrm{kg}(P<0.005)$ to $-0.3($ SD 0.7$) \mathrm{kg}(P<0.02)$ after correction for differences in ECW/TBW and ECW/height.

The application of several prediction formulas from the literature to both groups results in biased estimates, showing that prediction formulas are population-specific and can only be applied to other populations with care. Jenin et al. (1975) proposed the use of impedance ratios at different frequencies to classify subjects with disturbed water homeostasis, i.e. dehydration or oedema. However, as the variation in low: high frequency impedance ratio is relatively large, and the correlation with body-water distribution rather low $(r 0.64$, Fig. 3 ), the use of this ratio as a discriminator seems invalid. It is likely that the impedance ratio is an individual measure, determined not only by the distribution of ECW/TBW, but also 
determined by body build, i.e. relative extremity length, muscle distribution over the body. This would explain that, although the correlation of the index with ECW/TBW at a population level is low, changes in body-water distribution in an individual are always coincidental with changes in impedance ratio (Deurenberg et al. 1994).

In conclusion, multi-frequency impedance measurements enable independent assessments of ECW and TBW with coefficients of variation of about $5 \%$. The validity of the predicted values depends on body-water distribution. The use of $100 \mathrm{kHz}$ over $50 \mathrm{kHz}$ has no clear advantages.

The low:high frequency impedance ratio is not a valid measure for body-water distribution.

We would like to thank the participants and J. ten Brinke, C. Broekhoff, H. Cena, D. Jansen, C. Korbijn, E. Lusseveld, E. van Malkenhorst, C. Mamini, E. Peters, D. van der Scheer, T. Schoen and C. Trentani for their help in the measurements.

\section{REFERENCES}

Baumgartner, R. N., Chumlea, W. C. \& Roche, A. F. (1989). Estimation of body composition from bioelectrical impedance of body segments. American Journal of Clinical Nutrition 50, 221-226.

Bland, J. M. \& Altman, D. G. (1986). Statistical methods for assessing agreement between two methods of clinical measurements. Lancet i, 307-310.

Deurenberg, P. (1994). Multi-frequency impedance as a measure of body water compartments. In Body Composition Techniques and Assessment in Health and Disease, pp. 46-56 [P. S. W. Davies and T. J. Cole, editors]. Cambridge: Cambridge University Press.

Deurenberg, P., Broekhoff, C., Andreoli, A. \& de Lorenzo, A. (1994). The use of multi-frequency impedance in assessing changes in body water compartments. Age and Nutrition 5, 137-141.

Deurenberg, P., van der Kooy, K., Leenen, R. \& Schouten, F. J. M. (1989). Body impedance is largely dependent on the intra- and extra-cellular water distribution. European Journal of Clinical Nutrition 43, 845-853.

Deurenberg, P., van der Kooy, K., Leenen, R., Weststrate, J. A. \& Seidell, J. C. (1991). Sex- and age-specific prediction formulas for estimating body composition from bio-electrical impedance: a cross validation study. International Journal of Obesity 15, 17-25.

Durnin, J. V. G. A. \& Womersley, J. (1974). Body fat assessed from total body density and its estimation from skinfold thickness measurements in 481 men and women aged from 16 to 72 years. British Journal of Nutrition 32, 77-97.

Forbes, G. B. (1987), Human Body Composition. New York: Springer Verlag.

Fuller, N. J. \& Elia, M. (1989). Potential use of bioelectrical impedance of the 'whole body' and of body segments for the assessment of body composition: comparison with densitometry and anthropometry. European Journal of Clinical Nutrition 43, 779-791.

Hoffer, E. C., Meador, C. K. \& Simpson, D. C. (1969). Correlation of whole body impedance with total body water. Journal of Applied Physiology 27, 531-534.

Jenin, P., Lenoir, J., Roullet, C., Thomasset, A. L. \& Ducrot, H. (1975). Determination of body fluid compartments by electrical impedance measurements. Aviation, Space and Environmental Medicine 46, $152-155$.

Kleinbaum, D. G. \& Kupper, L. L. (1978). Applied Regression Analysis and Other Multivariable Methods. North Scituate, Massachusetts: Duxbury Press.

Kushner, R. F., Schoeller, D. A., Fjeld, C. R. \& Danford, L. (1992). Is the impedance index (ht ${ }^{2} /$ R) significant in predicting total body water? American Journal of Clinical Nutrition 56, 835-839.

Lukaski, H. C. \& Johnson, P. P. (1985). A simple, inexpensive method of determining total body water using a tracer dose of D20 and infrared absorption of biological fluids. American Journal of Clinical Nutrition 41, 363-370.

Lukaski, H. C., Johnson, P. E., Bolonchuck, W. W. \& Lykken, G. E. (1985). Assessment of fat free mass using bio-electrical impedance measurements of the human body. American Journal of Clinical Nutrition 41, 810-817.

Miller, M. E. \& Cappon, C. J. (1984). Anion exchange chromatographic determination of bromide in serum. Clinical Chemistry 30, 781-783.

Nyboer, J. (1970). Electrical Impedance Plethysmography, 2nd ed. Springfield, IL: C. C. Thomas Publishers.

Rush, S. R., Abildskov, J. A. \& McFee, S. (1963). Resistivity of body tissues at low frequencies. Circulation Research 12, 40-50.

Schwan, H. P. (1963). Determination of biological impedances. In Physical Techniques in Biological Research, vol. 6, pp. 323-407 [W. L. Nastuk, editor]. New York: Academic Press.

Segal, K. R., van Loan, M. D., Fitzgerald, P. I., Hodgdon, J. A. \& van Itallie, T. B. (1988). Lean body mass 
estimation by bioelectrical impedance analysis: a four site cross validation study. American Journal of Clinical Nutrition 47, 7-14.

Segal, K. R., Burastero, S., Chun, A., Coronel, P., Pierson, R. N. \& Wang, J. (1991). Estimation of extra cellular water and total body water by multiple frequency bio-electrical impedance measurements. American Journal of Clinical Nutrition 54, 26-29.

Settle, R. G., Foster, K. R., Epstein, B. R. \& Mullen, J. L. (1980). Nutritional assessment: whole body impedance and body fluid compartments. Nutrition and Cancer 2, 7280 .

Siri, W. E. (1961). Body composition from fluid spaces and density, analysis of methods. In Techniques for Measuring Body Composition, pp. 223-244 [J. Brozek and A. Henschel, editors]. Washington DC: National Academy of Sciences.

SPSS/PC (1990). V4.0 Manuals. Chicago, IL: SPSS Inc.

Svendson, O. L., Haarbo, J., Heitman, B. L., Gotfredsen, A. \& Christiansen, C. (1991). Measurement of body fat in elderly subjects by dual energy $\mathrm{x}$-ray absorptiometry, bioelectrical impedance and anthropometry. American Journal of Clinical Nutrition 53, 1117-1123.

Thomasset, A. L. (1962). Bio-electrical properties of tissue impedance measurements. Lyon Medical 201, 101-118.

Van Marken Lichtenbelt, W. D., Westerterp, K. R., Wouters, L. \& Luiendijk, S. C. (1994). Validation of bioelectrical impedance measurements as a method to estimate body-water compartments. American Journal of Clinical Nutrition 60, 159-166. 